Article

\title{
Evaluation of Close-Range Photogrammetry Image Collection Methods for Estimating Tree Diameters
}

\author{
Martin Mokroš ${ }^{1,2, *}$ (D), Xinlian Liang ${ }^{3,4}{ }^{1}$ Peter Surový ${ }^{2}$ (D), Peter Valent ${ }^{1}$, Juraj Čerňava ${ }^{1}$, \\ František Chudý ${ }^{1}$, Daniel Tunák ${ }^{1}$, Šimon Saloň ${ }^{1}$ and Ján Merganič ${ }^{5}$ \\ 1 Department of Forest Management and Geodesy, Faculty of Forestry, Technical University in Zvolen, \\ T. G. Masaryka 24, Zvolen 96053, Slovakia; peter.valent@tuzvo.sk (P.V.); juraj.cernava@tuzvo.sk (J.C.); \\ chudy@tuzvo.sk (F.C.); tunak@tuzvo.sk (D.T.); simon.salon@tuzvo.sk (S.S.) \\ 2 Faculty of Forestry and Wood Sciences, Czech University of Life Sciences Prague, 16500 Praha 6, Suchdol, \\ Czech Republic; surovy@fld.czu.cz \\ 3 Finnish Geospatial Research Institute, Geodeetinrinne 2, FI-02430 Masala, Finland; xinlian.liang@nls.fi \\ 4 Centre of Excellence in Laser Scanning Research, Academy of Finland, 02430 Helsinki, Finland \\ 5 Department of Forest Harvesting, Logistics and Ameliorations, Faculty of Forestry, Technical University in \\ Zvolen, T. G. Masaryka 24, Zvolen 96053, Slovakia; merganic@tuzvo.sk \\ * Correspondence: martin.mokros@tuzvo.sk; Tel.: +421-455-206-296
}

Received: 18 January 2018; Accepted: 7 March 2018; Published: 11 March 2018

\begin{abstract}
The potential of close-range photogrammetry (CRP) to compete with terrestrial laser scanning (TLS) to produce dense and accurate point clouds has increased in recent years. The use of CRP for estimating tree diameter at breast height (DBH) has multiple advantages over TLS. For example, point clouds from CRP are similar to TLS, but hardware costs are significantly lower. However, a number of data collection issues need to be clarified before the use of CRP in forested areas is considered effective. In this paper we focused on different CRP data collection methods to estimate DBH. We present seven methods that differ in camera orientation, shooting mode, data collection path, and other important factors. The methods were tested on a research plot comprised of European beeches (Fagus sylvatica L.). The circle-fitting algorithm was used to estimate DBH. Four of the seven methods were capable of producing a dense point cloud. The tree detection rate varied from $49 \%$ to $81 \%$. Estimates of DBH produced a root mean square error that varied from $4.41 \mathrm{~cm}$ to $5.98 \mathrm{~cm}$. The most accurate method was achieved using a vertical camera orientation, stop-and-go shooting mode, and a path leading around the plot with two diagonal paths through the plot. This method also had the highest rate of tree detection $(81 \%)$.
\end{abstract}

Keywords: close-range photogrammetry; diameter at breast height; point cloud; circle fitting; forestry

\section{Introduction}

Forest inventory is the primary tool of forest management to collect data on various forest attributes that help managers make better decisions in consideration of multiple objectives. Tree diameter at breast height $(\mathrm{DBH})$ is one of the most important attributes in forestry. It provides fundamental information about trees and forest stands. Based on DBH, tree attributes, such as basal area, tree height, tree volume, and crown characteristics, can be estimated [1-3]. The DBH measurement is typically measured using a calliper or girth tape. Over time, various non-contact dendrometers have been developed to measure DBH (e.g., optical callipers, Bitterlich's relascope, dendrometers). Other tools have also been developed to measure stem diameters at unreachable heights; however, their accuracy is typically lower compared to the contact dendrometers [4]. For forest inventory purposes, DBH is typically measured within sample plots. The size of the plots is selected based on varying factors [5]. Acquiring 
DBH measurements using these methods can be financially and personally demanding. Therefore, there is a continuous effort to search for alternative efficient methods to estimate DBH.

Terrestrial laser scanning (TLS) is another tool that can potentially measure DBH, tree height, tree volume, crown characteristics, or several other characteristics. The authors have successfully estimated DBH with appropriate accuracy (RMSE $=1-3 \mathrm{~cm}$ ) using TLS in previous studies [6-10]. Another advantage of TLS is the potential to estimate other trees and stand characteristics. Tree position [11,12], height [13,14], volume [15], and crown characteristics [16,17], among others, can be estimated from TLS point clouds. However, TLS hardware is still relatively expensive and, when the multi-scan method is used, the data acquisition requires multiple artificial objects carefully placed to match scans to produce accurate DBH estimates.

In recent years, due to the development of image matching algorithms and computer hardware, close-range photogrammetry (CRP) has become an alternative solution that provides terrestrial and aerial point cloud densities similar to TLS methods, and higher density point clouds compared to airborne laser scanning. The use of CRP for forestry is an emerging topic; the combination of CRP and unmanned aerial vehicles (UAV) can potentially revolutionize information collection methods for forests and individual trees [18-23]. The main advantage of terrestrial CRP is that it produces similar outputs with lower hardware costs when compared to TLS systems. Only a few recent studies have explored this new approach [24-28]; they reported a root mean square error of DBH estimation from CRP that varied from $0.91 \mathrm{~cm}$ to $6.79 \mathrm{~cm}$.

There are currently three common TLS methods to collect forest stand data; they include single-scan, multiple-scan, and multi-single-scan methods [29]. The single-scan method collects data from one position (usually the middle of the plot). The multi-scan method scans the forest from multiple positions. Artificial objects are used to merge the point clouds from different positions. The multi-single-scan method is similar to the multi-scan method, but the registration is at the feature levels rather than the data level using artificial objects. The method detects the position of individual trees within the scans, and it then merges the scans based on the tree positions [10].

The CRP method generates a point cloud from a series of overlapped images. A couple of data acquisition methods can be used. For example, in the stop-and-go method, the operator takes images in a static position and then moves to another position and takes another static image [24,30]. The second approach is a mobile method. The operator holds the camera and automatically shoots the images (burst mode) during the movement [26]. In a previous study [25], the authors captured images only from the center of the plot, but from multiple cameras arranged on a special rig. It is not possible to compare these previous studies because they have used different cameras, data collection methods, tree species, plot size, etc. However, those studies suggest that CRP has a high potential to accurately estimate DBH.

In this study we compared seven different CRP data collection methods to evaluate their potential to generate accurate point clouds of forest stands. Based on the generated point clouds, we estimated DBH to assess the estimation accuracy of the various methods. The methods differed mainly by the data collection path and camera shooting modes; four different paths and two camera shooting modes were used. For further development and implementation of CRP to forestry practices, it is crucial to firstly determine a suitable approach for data collection within forest stands.

\section{Materials and Methods}

\subsection{Study Site}

The study site is situated within a forest stand in the Kremnica Mountains in central Slovakia. The forest stand lies within the Forest Enterprise of the Technical University in Zvolen. The plot was $35 \mathrm{~m} \times 35 \mathrm{~m}$ in size with a slope of less than $5^{\circ}$ throughout the plot. In total, 74 European beeches (Fagus sylvatica L.) were included in the plot; we used only trees with a DBH larger than $7 \mathrm{~cm}$ for this 
study (67 of the 74 trees). The average DBH was $25.3 \mathrm{~cm}$, and it varied from $7 \mathrm{~cm}$ to $55 \mathrm{~cm}$ (Figure 1). There was no understory or shrubs within the plot, and the ground was covered with dried leaves.

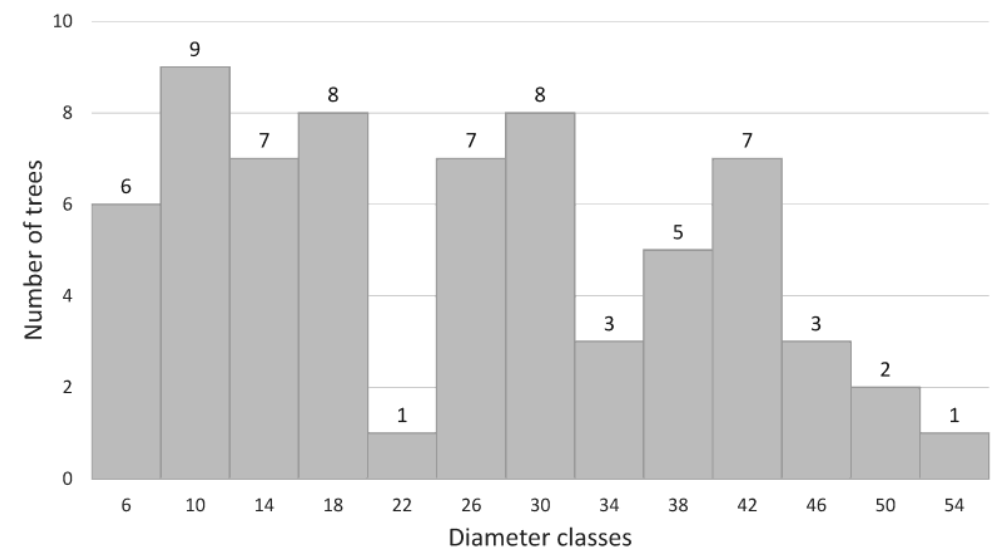

Figure 1. The diameter at breast height $(\mathrm{DBH})$ distribution of all 67 study trees from the plot.

\subsection{Reference Data}

The positions of all trees were measured by the Topcon GPT-9000M total station at $1.3 \mathrm{~m}$ height. The positions were used to pair the reference measurements with estimates of DBH of individual trees. In the post-processing, the positions were re-calculated based on the measured DBH and the direction of measurement to represent the center of the trunk. The DBH of all trees was measured by a girth tape and then recalculated to diameter.

\subsection{Close-Range Photogrammetry Data Collection}

Data collection was conducted using a Canon EOS 5D Mark II camera. It is a digital single-lens reflex camera with a CMOS $362 \times 4 \mathrm{~mm}$ sensor. The maximum resolution is 21.1 megapixels $(56,163 \times 744$ pixels). We used full resolution with the Canon EF $35 \mathrm{~mm} \mathrm{f/2} \mathrm{IS} \mathrm{USM} \mathrm{lens,} \mathrm{and} \mathrm{a}$ JPEG file format was used. Seven different methods were used to collect the images within the research plot. The methods differed by camera orientation, shooting mode, path, and holding method (Table 1); they also differed by camera settings. During image collection, manual focus was used for all methods. The focus was set to $3 \mathrm{~m}$ and fixed by tape on the lens. The data collection was performed over a period of two days. Methods 1 to 4 were conducted on the first day with a clear sky and no clouds. On the second day the weather changed and the sky was cloudy as we conducted methods 5 to 7 . Settings were selected to produce similar images within the methods as much as possible.

Table 1. Seven methods used to conduct the data collection on the research plot.

\begin{tabular}{cccccccc}
\hline Method & $\begin{array}{c}\text { Camera } \\
\text { Orientation }\end{array}$ & $\begin{array}{c}\text { Shooting } \\
\text { Mode }\end{array}$ & Path & $\begin{array}{c}\text { Holding } \\
\text { Method }\end{array}$ & Aperture & ISO & $\begin{array}{c}\text { Shutter } \\
\text { Speed }\end{array}$ \\
\hline 1 & Horizontal & Mobile & Waves & Gimbal & F/10 & 400 & $1 / 400$ \\
2 & Horizontal & Mobile & Waves & Pole & F/10 & 400 & $1 / 400$ \\
3 & Horizontal & Mobile & Waves & Handheld & F/10 & 400 & $1 / 400$ \\
4 & Vertical & Mobile & Waves & Handheld & F/10 & 400 & $1 / 400$ \\
5 & Vertical & Stop-and-go & Outside & Handheld & F/7.1 & 400 & $1 / 50$ \\
6 & Vertical & Stop-and-go & Outside/Inside & Handheld & F/7.1 & 400 & $1 / 50$ \\
7 & Vertical & Stop-and-go & Strips & Handheld & F/7.1 & 800 & $1 / 50$ \\
\hline
\end{tabular}

Two camera orientations were used. The horizontal orientation was used when the camera was attached to the DJI Ronin-M (handheld 3-axis camera gimbal) and the $2.5 \mathrm{~m}$ long pole, and when the camera was handheld. Methods 1 to 4 used the mobile (burst) shooting mode at high speed; 
approximately two images per second collected. The camera captured images simultaneously during the walk following the trace. This approach was also used when the camera was handheld for both camera orientations. The second data collection method was the stop-and-go method; for this approach the photographer moved between the positions and took the images only when they were still at a designated position.

Four different paths were performed (Figure 2). The "Waves" path (Figure 2a) went through the plot using the mobile shooting mode. The photographer walked continuously through the plot without stops (interruptions). Altogether six line paths were made; three lines ran perpendicular to another three lines, and looped paths at the plot edges interconnected the lines to ensure sufficient overlap between the images.

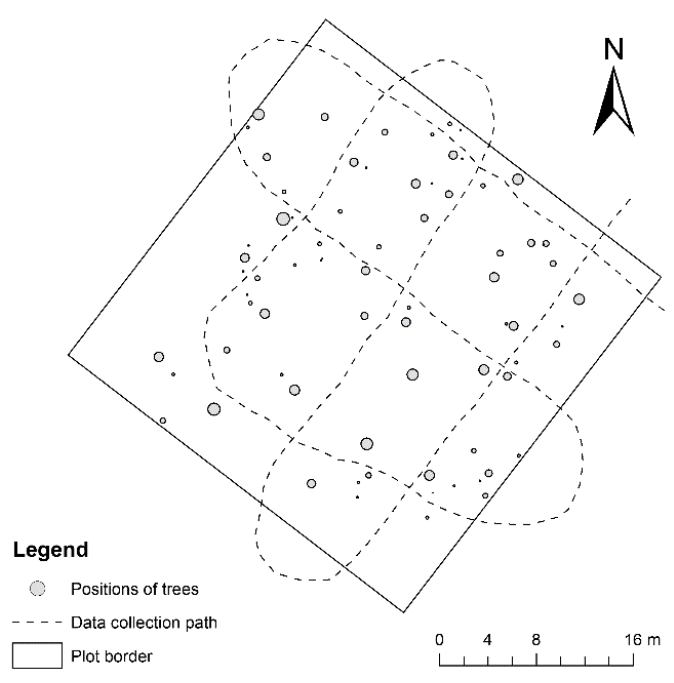

(a)

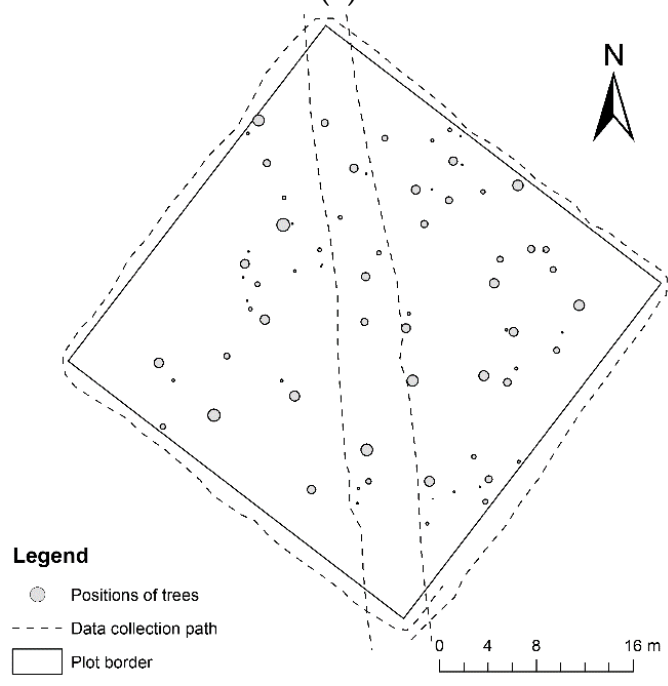

(c)

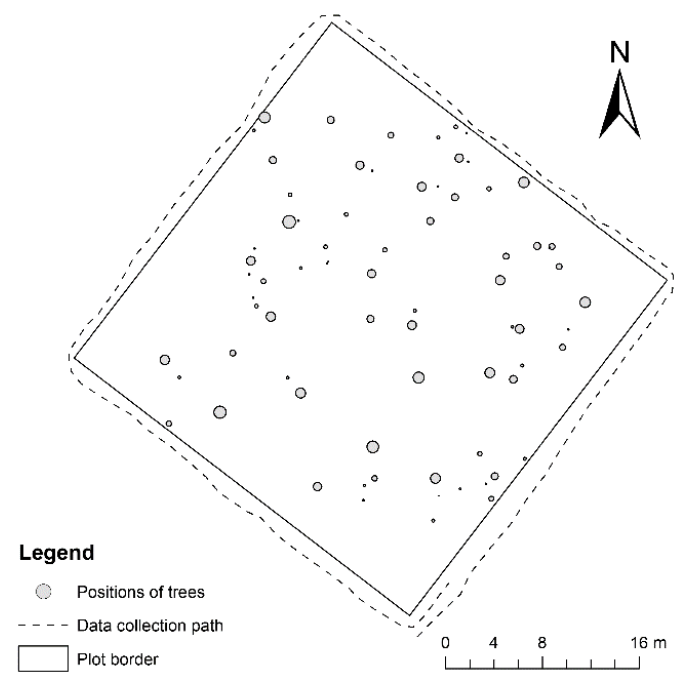

(b)

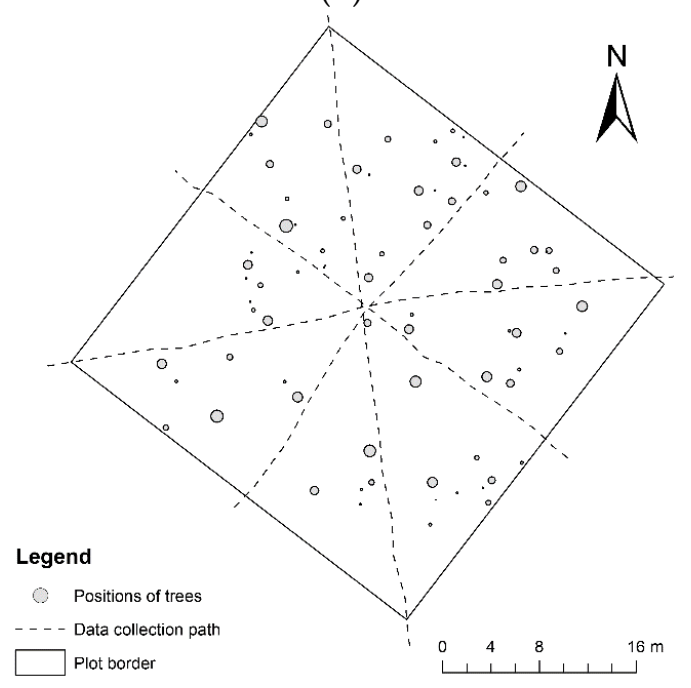

(d)

Figure 2. Illustration of data collection paths of all the methods used: "Waves" path (a); "Outside" path (b); "Outside/Inside" path (c); and "Strips" path (d).

The "Outside" path (Figure 2b) was defined by the perimeter of the plot; the photographer moved by small steps between positions and took pictures of the plot. The "Outside/Inside" path (Figure 2c) was a combination of the "Outside" path with two additional parallel traces across the diagonal of the plot. The images were collected in the same manner as the "Outside" path method. The photographer took pictures perpendicular to the direction of the path and pointing at the opposite path. 
The last method, "Strips" path, was a set of eight paths (Figure 2d). Each path started and finished outside of the plot, and all paths crossed through the center of the plot. The camera was pointing in the path direction. The six targets were placed in the center of the plot with care to ensure they could all be seen from each of the eight paths.

The number of images varied from 440 to 1552 for the various methods, and the data collection time varied from $9 \mathrm{~min}$ to $40 \mathrm{~min}$ (Table 2). The greatest number of images was collected using the mobile method (method 4) when the burst mode was used; it also took the least amount of time. Data collection using method 7 required the greatest amount of time.

Table 2. Comparison of the number of images and data collection time of the various methods.

\begin{tabular}{ccc}
\hline Method & No. of Images & Data Collection Time (min) \\
\hline 1 & 1191 & 11 \\
2 & 1282 & 16 \\
3 & 1271 & 9 \\
4 & 1552 & 17 \\
5 & 440 & 21 \\
6 & 656 & 32 \\
7 & 635 & 40 \\
\hline
\end{tabular}

We placed multiple range poles within the plot prior to collecting the data for the purposes of scaling and orientation. The range poles were placed in the corners of the plot and the middle of each line connecting the corners. Each range pole had a bulls-eye spirit level to stabilize the Z-axis of the pole. Additionally, in the case of method 7, we placed six targets (size A4) in the middle of the plot (Figure 3). These targets were later used for the point cloud merging of different strips.

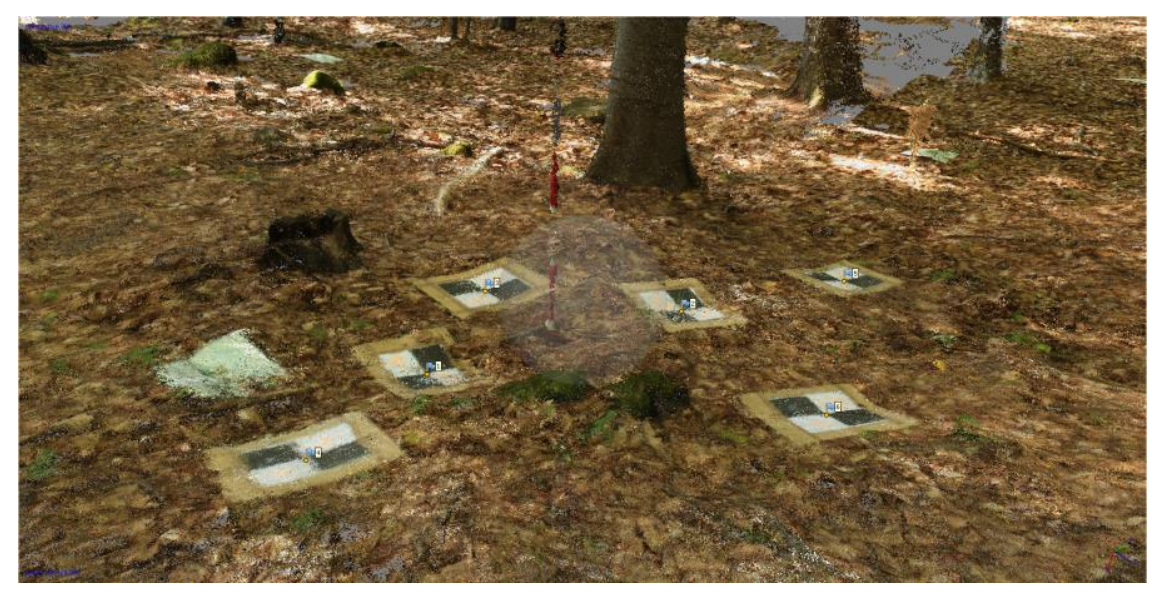

Figure 3. Visualization of a merged dense point cloud generated from images collected using method 7.

Six targets used to merge the strips are evident in the image.

\subsection{Data Processing of Images}

Images were processed and dense point clouds were generated in Agisoft Photoscan Professional 1.2.6 software (Agisoft LCC, Saint Petersburg, Russia). The workflow consisted of three main steps. Images were initially aligned using the module "Align images". We used settings that reduced computer memory demands. The image resolution was reduced, and overlapping pairs of images were selected and aligned in full resolution. The second option was more demanding on computer memory, but it can produce better results. The algorithm used full resolution and all images were compared in all possible combinations. The advanced settings were "key point limit" and "tie point limit". The key point limit is the maximum number of points detected for each image. The tie point 
limit is the maximum number of points that will be used for image matching. The key point limit was set to 40,000 as the default, and the tie point limit was set to 4000 as the default. We used "generic pair preselection", "high accuracy", and default key and tie point limits (40,000 and 4000). When an alignment was not successful, the key and tie point limits were doubled; if this change did not help, both limits were changed to 0 , which imposes no limits on the number of key and tie points.

The processing of the dataset collected using method 7 (Table 1) required additional steps before scaling and orientation. The eight strips were aligned separately, and then for each dataset the six markers were placed on the targets in the plot center (Figure 3). Based on those points, the strips were then merged into a single point cloud.

Once the images were successfully aligned, tie points were scaled and oriented. The range poles were used for scaling and orientation purposes. Four markers were placed on the first range pole. The range pole was divided by $20 \mathrm{~cm}$ red and white sections. Markers were placed at the beginning of each section. We set the $X Y Z$ coordinates for each of the four markers. The $X, Y$, and $Z$ coordinates of the bottom markers were set to 0,0 , and 10, respectively. The $X Y$ coordinates were not changed for other markers, and the $\mathrm{Z}$ coordinate was based on the distance from the bottom of the poles (i.e., 10.2, 10.4, and 10.6, respectively). The whole project was scaled and the Z-axis was oriented based on these markers. In our case, the XY axis orientation was not important. Two markers were placed on each of remaining range poles; the scale bar was made based on these markers for each pole. The scale bars were used as 'Check Scale Bars' to validate the accuracy of the scaling.

The final step was to create the dense point cloud using the Agisoft Photoscan software. We used high quality and aggressive depth filtering for all datasets.

\subsection{Estimation of Diameter at Breast Height}

A circle fitting algorithm was used to estimate DBH. The algorithm searched for the diameter and the position of the circle center in 2D space on the cross section of the trunk at breast height $(1.3 \mathrm{~m})$. An initial method was used to estimate the diameter and approximate circle center position. Then, the refining method was used to improve the accuracy. The minimum bounding box, the centroid, and the maximum distance methods were used as initial methods. For refining methods, the Monte Carlo and the optimal circle could be used. A detailed explanation of all methods we used can be found in [31]. We used the automatic selection for the initial method and the optimal circle method as the refining method. The workflow to obtain the cross section of the trunks consisted of multiple steps. Initially, an empty grid with a $0.5 \mathrm{~m} \times 0.5 \mathrm{~m}$ cell size was created based on the point cloud extent. An algorithm calculated the minimum $Z$ coordinate value for each cell of the grid. Based on the created grid, normalized $Z$ values for each point of the point cloud were calculated. We then created the point cloud cross section. The cross section consists of points with normalized $Z$ values ranging from $1.275 \mathrm{~m}$ to $1.325 \mathrm{~m}$. The cross section was spatially clustered to groups based on the minimum point limit and the maximum distance limit. We used $5 \mathrm{~cm}$ as a maximum distance limit and 100 points as a minimum points limit. Groups were then visually checked using the cross section analyst. Groups considered to be noise were manually deleted. The entire workflow was conducted using DendroCloud 1.21 software (Technical University in Zvolen, Zvolen, Slovakia) [32].

\subsection{Data Evaluation}

The positions of trees measured by total station were synchronized with estimates of DBH in ArcGIS for Desktop software (Environmental Systems Research Institute (ESRI), Redlands, CA, USA). For each tree, the estimated position and DBH layers were overlaid with reference measurements and paired.

The error of estimation was calculated as the difference between the reference $\mathrm{DBH}\left(\mathrm{DBH}_{\mathrm{r}}\right)$ and estimated $\mathrm{DBH}\left(\mathrm{DBH}_{\mathrm{e}}\right)$ of the trunk. The bias was calculated as the average of errors. Based on the errors, the root mean square error and the relative root mean square error were calculated.

Paired-samples $t$-tests were used to test for significant differences between measured and estimated diameters and the various methods used. The errors of the methods were tested using 
paired-samples $t$-tests. To test the significance of the estimation of DBH (i.e., null hypothesis: bias $=0$ ), a single-sample t-test was used.

\section{Results}

Four of the seven methods were successfully processed into dense point clouds. Methods 1, 2, and 4 failed to align. The tree identifications and estimates of DBH were conducted for the successfully aligned methods (methods 3 and 5-7).

\subsection{Tree Detection Rates}

For tree detection within the plot, we achieved the best results with an omission error equal to 13 using method 6; the highest omission error was 34 (method 7; Table 3). Overall accuracy varied from $49 \%$ to $81 \%$. The commission error was present when methods 5 and 6 were used; small trees (DBH under seven centimeters) caused commission errors.

Table 3. Omission and commission errors and overall accuracy for methods of data collection that were successfully processed into dense point clouds (67 reference trees).

\begin{tabular}{cccc}
\hline Method & Omission & Commission & Overall Accuracy \\
\hline 3 & 18 & 0 & $73 \%$ \\
5 & 16 & 2 & $76 \%$ \\
6 & 13 & 3 & $81 \%$ \\
7 & 34 & 0 & $49 \%$ \\
\hline
\end{tabular}

\subsection{Estimation of Diameter at Breast Height}

The DBH was estimated for all identified trees of all successfully aligned methods. A boxplot of DBH measured by girth tape and estimated DBHs using the aligned methods are shown in Figure 4. Paired-samples $t$-tests indicated the diameters of methods 5 and 6 were significantly different from the reference diameters ( $p=0.0006$ and $p=0.012$, respectively).

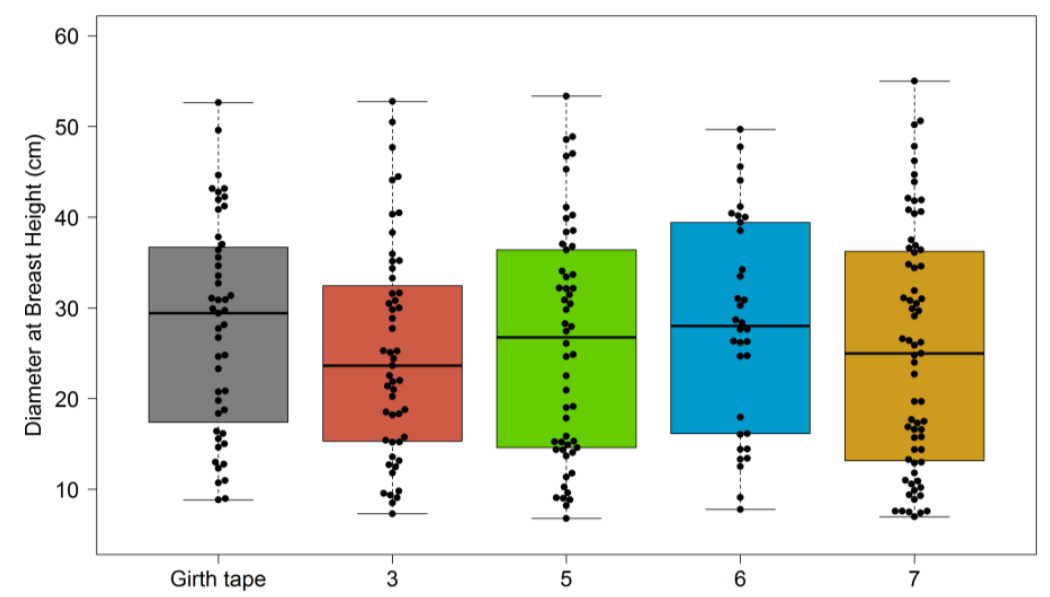

Figure 4. Boxplot of measured and estimated diameters at breast height (DBH) with one-dimensional scatter plot of individual DBHs.

The most accurate DBH estimation results were achieved using method 6 (relative RMSE $=16.67 \%$ ); the worst results $(20.93 \%)$ were derived from method 4 (Table 4). Paired-samples $t$-tests suggested that DBH errors using the various methods were not statistically different. 
Table 4. The bias and RMSE resulting from the estimation of DBH.

\begin{tabular}{cccc}
\hline Method & Bias $(\mathbf{c m})$ & RMSE (cm) & RMSE\% \\
\hline 3 & -1.02 & 5.98 & 20.93 \\
5 & -2.63 & 5.01 & 18.92 \\
6 & -1.49 & 4.41 & 16.67 \\
7 & -0.46 & 5.29 & 18.39 \\
\hline
\end{tabular}

Bias using single-sample $t$-tests suggested that we could reject the hypothesis that the error of methods 5 and 6 was equal to 0 (alpha level of 0.05). A boxplot of errors of estimation of DBH is shown in Figure 5.

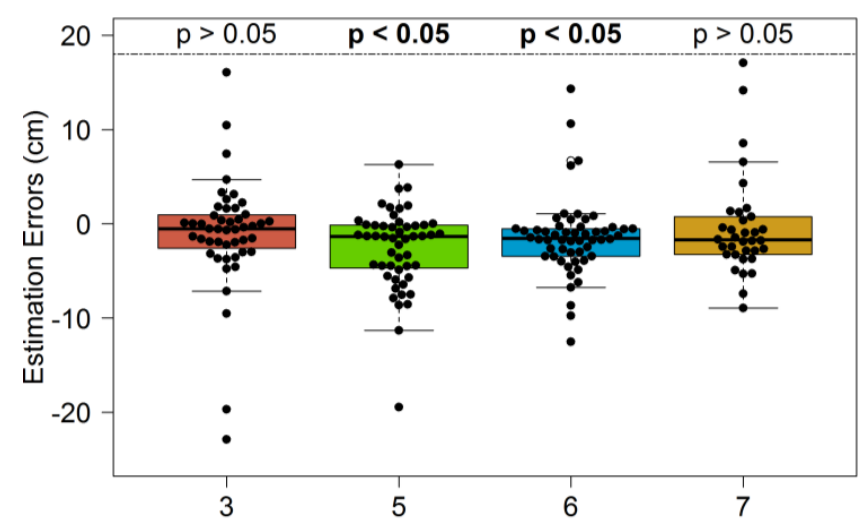

Figure 5. Boxplot of estimation of DBH errors with one-dimensional scatter plot of individual errors using the aligned methods. $p$-values $<0.05$ indicate the bias of the method was significantly different from 0 .

\section{Discussion}

Seven different setups of the close-range photogrammetry were used to collect images. We were able to create dense point clouds from four methods. All methods that used the stop-and-go approach were successful; only one method that used the mobile approach successfully generated a dense point cloud. The omission error varied from 13 to 34 , and the overall accuracy varied from $49 \%$ to $81 \%$. The most accurate estimations of DBH $($ RMSE $=4.41 \mathrm{~cm})$ were obtained using method 6 . Only one of the four methods that used the mobile shooting mode was successfully processed to generate a point cloud, but it produced the worst results with an estimation of DBH RMSE of $5.98 \mathrm{~cm}$.

\subsection{Efficiency of Image Collection Methods}

Four methods were successfully aligned and allowed for DBH estimations. Both shooting modes were represented among the successful methods. The stop-and-go shooting mode provided more consistent results for point cloud generation and accurate estimates of DBH. Another advantage of the stop-and-go shooting mode was that the smaller number of images decreased the cost of point cloud generation (e.g., data-processing time) and the amount of hard drive disk space required. For example, method 3, which produced 1272 images, required 12 GB of hard drive disk storage, but method 5 , which produced only 440 images, required only 3.47 GB of hard drive disk space; a difference of 8.53 GB, which only considers the collected data, not additional storage requirements related to post-processing. Data collection using the stop-and-go approach was more efficient than the mobile approaches; however, during the field portion of the process, the mobile method was quicker and more efficient. The time needed for data collection varied from $9 \mathrm{~min}$ to $40 \mathrm{~min}$ (Table 2). If TLS was to be used for this research plot, we assume that five positions would be sufficient to cover the entire plot. As an example, using scanners from FARO Technologies (Lake Mary, FL, USA), they would need to be stationed in one position for approximately $10 \mathrm{~min}$; considering the time required to move 
between positions, we estimated that 60 to 70 min would be required to scan the plot. Also, because the point cloud is generated during the field measurements, the post-processing would be less time consuming compared to CRP. It is important to consider multiple factors and their interactions in terms of resources (e.g., time, money, etc.) and accuracy (e.g., estimation of DBH) when choosing the most adequate technology.

In our opinion, another advantage of the stop-and-go shooting mode, when the lightning conditions are the same for all data collection methods, is the possibility to decrease the shooting speed because the camera is in a stable position. This would also allow the ISO to be lower, and the aperture can be set higher. For the mobile shooting mode, assuming consistent lighting conditions, the shooting speed must be higher to avoid blurry images, and, to obtain bright images, the ISO must be higher and the aperture lower, which could produce noisy images.

Methods 5 and 6 differed only by the path of shooting; method 6 had two extra diagonal paths through the plot. Method 6 provided the best results with an omission error of 19.4\%; the RMSE and omission error decreased with the addition of the diagonal paths (Tables 3 and 4). We assume that two additional diagonal paths could decrease the omission error.

\subsection{Alignment of Images}

Methods 1, 2, and 4 did not successfully align. Multiple different settings within the Agisoft Photoscan software were used in an attempt to align the datasets. Furthermore, the images were split into groups based on the path to align lines separately, and even then the images were not aligned. All three methods used the mobile shooting mode. For methods 1 and 2, the camera was not held by hand, but by gimbal and pole, respectively. It was difficult to ensure the overlap between images during the shooting, especially when the pole was used. When the gimbal was used, the operator had to hold it with both hands following the path and ensuring the gimbal was working correctly. On the other hand, we have used the DJI Ronin M, but it is difficult to see the display of the camera with this device. There are various other gimbals on the market that can be held using one hand and allow the operator to see the camera display. We assume this could lead to better overlap and results.

The only difference between methods 3 and 4 was the orientation of the camera; vertical orientation was used for method 4 . In many cases the overlap between images was not satisfactory. When the camera was vertically oriented, even very slight operator movements to the side yielded insufficient overlaps. It should be noted however that a camera with a $35 \mathrm{~mm}$ lens was used.

\subsection{Tree Detection Rates}

Another important issue to consider is the detection rate of trees within the plot. We achieved $80.6 \%$ detection rate as a best result when method 6 was used. Our results were similar to other previous studies that focused on tree detection using close-range photogrammetry data. In one study, [33], the authors reported an $84 \%$ detection rate of individual trees. They also tested a personal laser scanning method that achieved a $92 \%$ detection rate, while TLS achieved a $100 \%$ detection rate. In another study, [25], the authors reported a $76 \%$ detection rate of individual trees within plots. For forest inventory purposes, it is very important to be able to guarantee a $100 \%$ detection rate of all trees over seven centimeters DBH. Therefore, future research should emphasize data collection methods that provide a $100 \%$ detection rate. Using TLS, there are approaches used that consider the shadowing (occlusion) of trees [34-36]; similar approaches should be considered for use with CRP methods.

\subsection{Estimation of Diameter at Breast Height}

The estimation of DBH RMSE varied from $4.41 \mathrm{~cm}$ to $5.98 \mathrm{~cm}$. Variability was attributed to multiple factors, but the main factor that highly influenced the error of estimation was the scaling method used during the point cloud generation. Range poles were distributed within the study site for scaling and orientation purposes (Table 5). Based on our results, we suggest a different approach to scale the point clouds. Future research should focus on an automatic scaling approach. It would 
be possible to detect the positions with known distances between them. Placing the points manually for scaling is challenging, whether they are reference sticks or tree pairs [33]. In study [26], the point cloud was scaled and oriented based on 10 ground control points that were measured by total station. They achieved an estimation of DBH RMSE of $1.80 \mathrm{~cm}$ when the circle-fitting algorithm was used; we presume that a similar method of scaling could lead to comparable results.

Table 5. Distance error of the scaling process of the point clouds with number of reference range poles and scale bars used.

\begin{tabular}{cccc}
\hline Method & Distance Error $(\mathbf{c m})$ & No. of Reference Sticks & No. of Scale Bars \\
\hline 3 & 0.54 & 4 & 4 \\
5 & 0.75 & 5 & 8 \\
6 & 0.51 & 7 & 11 \\
7 & 0.61 & 8 & 14 \\
\hline
\end{tabular}

Another contributing factor to the observed variability of estimation of DBH RMSE was the circle fitting approach we used to estimate DBH. The authors of study [26] used the circle-fitting and convex hull algorithms. They reported that the estimation of DBH RMSE of the circle-fitting approach was almost two times worse than the convex-hull method. Future research should focus on testing more complex algorithms, as is the case for TLS data $[37,38]$.

Figure 6 displays the cross sections of two trees from four data collection methods. One was situated in the middle of the plot, and the other tree was at the border of the plot. From this example we can see that method 6 almost fully reconstructed the trunk from the center of the plot. All other methods provided incomplete reconstructions from the center of the plot. The tree at the border was successfully reconstructed by methods $5-7$. In the case of method 7, a minor shift between the semicircles is evident; the shift was caused by the merging error between the strips. Method 3, which used the mobile method, produced similar, but incomplete, trunk cross sections for trees at the center and at the border of the plot.

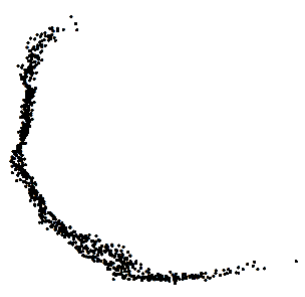

method 3

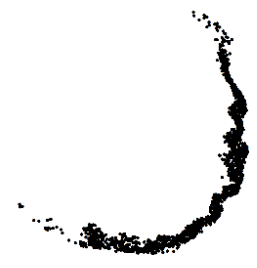

method 3

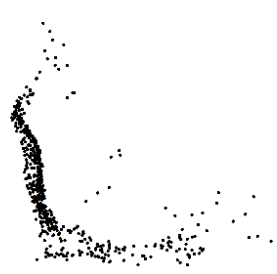

method 5

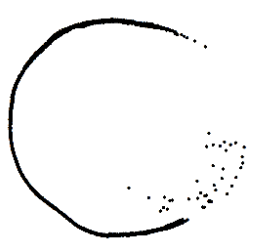

method 5

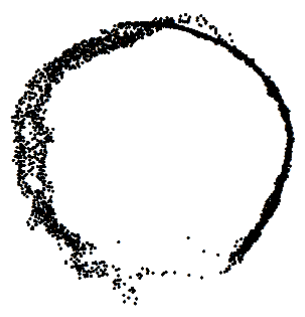

method 6

(a)

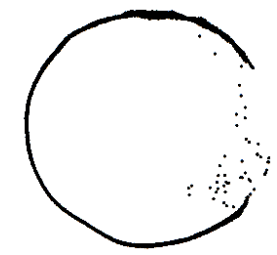

method 6

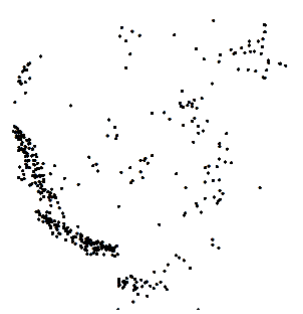

method 7

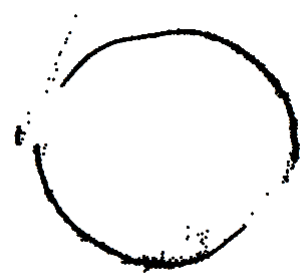

method 7

(b)

Figure 6. The cross section at $1.3 \mathrm{~m}$ of a single tree in the middle of the plot (a) and a single tree situated near the border of the plot (b) from all successful methods (methods 3, 5-7). 


\section{Conclusions}

The main objective of our study was to determine the most suitable method to collect images to be used to generate point clouds representative of a forest stand, with the aim to estimate diameters at breast height. We used seven different methods that differed in camera orientation, shooting mode, data collection path, and holding method. Point clouds were successfully created from four of the seven methods. The most accurate method achieved an estimation of DBH RMSE of $4.41 \mathrm{~cm}$. The "Outside/Inside" method used a stop-and-go shooting mode and a path on the outside of the plot with two diagonal paths through the center of the plot. The camera was held by hand, and a vertical orientation was used. This method also achieved the highest tree detection rate $(81 \%)$. Our results have demonstrated the impact of various CRP data collection methods on estimations of DBH and tree detection rates. Further research should focus on data collection methods that will increase the overall accuracy to $100 \%$.

Supplementary Materials: The point clouds are available at mapy.tuzvo.sk/CRPmethods.

Acknowledgments: This work was supported by the Scientific Grant Agency of the Ministry of Education, Science, Research and Sport of the Slovak Republic under the grant VEGA 1/0881/17, and by the Slovak Research and Development Agency through grant No. APVV-15-0714 ("Mitigation of climate change risk by optimization of forest harvesting scheduling"), by grant No. APVV-0069-12 ("New technology of nature management (NEWTON)"), and by grant No. CZ.02.1.01/0.0/0.0/16_019/0000803 ("Advanced research supporting the forestry and wood-processing sector's adaptation to global change and the 4th industrial revolution") financed by OP RDE. Xinlian Liang would also like to thank financial aid from the Finnish Academy projects "Centre of Excellence in Laser Scanning Research (CoE-LaSR) (272195)".

Author Contributions: Martin Mokroš wrote the initial draft of the manuscript; Martin Mokroš, Xinlian Liang, Peter Surový, Peter Valent, Juraj Čerňava, and Ján Merganič contributed to the writing and reviewing of the final manuscript; Martin Mokroš, Xinlian Liang, and Peter Surový contributed to the initial proposal of the methodology; Martin Mokroš, Peter Valent, Juraj Čerňava, František Chudý, Daniel Tunák, and Šimon Saloň were responsible for image and reference data acquisition and data processing.

Conflicts of Interest: The authors declare no conflict of interest.

\section{References}

1. Leech, J.W. Estimating crown width from diameter at breast height for open-grown radiata pine trees in South Australia. Aust. For. Res. 1984, 14, 333-337.

2. Gering, L.R.; May, D.M. The relationship of diameter at breast height and crown diameter for four species groups in Hardin County, Tennessee. South. J. Appl. For. 1995, 19, 177-181.

3. Husch, B.; Beers, T.W.; Kershaw, J.A., Jr. A. Forest Mensuration; John Wiley \& Sons: Hoboken, NJ, USA, 2002.

4. Clark, N.; Wynne, R.; Schmoldt, D. A review of past research on dendrometers. For. Sci. 2000, 46, 570-576.

5. Kangas, A.; Maltamo, M. Forest Inventory: Methodology and Applications; Springer Science \& Business Media: Berlin, Germany, 2006; Volume 10.

6. Simonse, M.; Aschoff, T.; Spiecker, H.; Thies, M. Automatic determination of forest inventory parameters using terrestrial laser scanning. Proc. Scandlaser Sci. Work. Airborne Laser Scanning For. 2003, 2003, 1-7.

7. Bienert, A.; Scheller, S.; Keane, E.; Mullooly, G.; Mohan, F. Application of Terrestrial Laser Scanners for the Determination of Forest Inventory Parametrs. Int. Arch. Photogramm. Remote Sens. Spat. Inf. Sci. 2006, 36, 2005-2008.

8. Maas, H.-G.; Bienert, A.; Scheller, S.; Keane, E. Automatic forest inventory parameter determination from terrestrial laser scanner data. Int. J. Remote Sens. 2008, 29, 1579-1593. [CrossRef]

9. Brolly, G.B.; Király, G.K. Algorithms for Stem Mapping by Means of Terrestrial Laser Scanning. Acta Silv. Lignaria Hung. 2009, 5, 119-130.

10. Liang, X.; Hyyppä, J. Automatic stem mapping by merging several terrestrial laser scans at the feature and decision levels. Sensors 2013, 13, 1614-1634. [CrossRef] [PubMed]

11. Ritter, T.; Schwarz, M.; Tockner, A.; Leisch, F.; Nothdurft, A. Automatic mapping of forest stands based on three-dimensional point clouds derived from terrestrial laser-scanning. Forests 2017, 8, 265. [CrossRef]

12. Yang, B.; Dai, W.; Dong, Z.; Liu, Y. Automatic forest mapping at individual tree levels from terrestrial laser scanning point clouds with a hierarchical minimum cut method. Remote Sens. 2016, 8, 372. [CrossRef] 
13. Huang, H.; Li, Z.; Gong, P.; Cheng, X.; Clinton, N.; Cao, C.; Ni, W.; Wang, L. Automated methods for measuring DBH and tree heights with a commercial scanning lidar. Photogramm. Eng. Remote Sens. 2011, 77, 219-227. [CrossRef]

14. Moskal, L.M.; Zheng, G. Retrieving Forest Inventory Variables with Terrestrial Laser Scanning (TLS) in Urban Heterogeneous Forest. Remote Sens. 2011, 4, 1-20. [CrossRef]

15. Liang, X.; Kankare, V.; Yu, X.; Hyyppa, J.; Holopainen, M. Automated stem curve measurement using terrestrial laser scanning. IEEE Trans. Geosci. Remote Sens. 2014, 52, 1739-1748. [CrossRef]

16. Henning, J.G.; Radtke, P.J. Ground-based Laser Imaging for Assessing Three-dimensional Forest Canopy Structure. Photogramm. Eng. Remote Sens. 2006, 72, 1349-1358. [CrossRef]

17. Fleck, S.; Obertreiber, N.; Schmidt, I.; Brauns, M.; Jungkunst, H.F.; Leuschner, C. Terrestrial Lidar Measurements for Analysing Canopy Structure in an Old-Growth Forest. Available online: https:/ / www.researchgate.net/publication/228755139_Terrestrial_lidar_measurements_for_analysing_ canopy_structure_in_an_old-growth_forest (accessed on 30 January 2018).

18. Getzin, S.; Nuske, R.S.; Wiegand, K. Using unmanned aerial vehicles (UAV) to quantify spatial gap patterns in forests. Remote Sens. 2014, 6, 6988-7004. [CrossRef]

19. Guerra-Hernández, J.; González-Ferreiro, E.; Sarmento, A.; Silva, J.; Nunes, A.; Correia, A.C.; Fontes, L.; Tomé, M.; Díaz-Varela, R. Using high resolution UAV imagery to estimate tree variables in Pinus pinea plantation in Portugal. For. Syst. 2016, 25. [CrossRef]

20. Zhang, J.; Hu, J.; Lian, J.; Fan, Z.; Ouyang, X.; Ye, W. Seeing the forest from drones: Testing the potential of lightweight drones as a tool for long-term forest monitoring. Biol. Conserv. 2016, 198, 60-69. [CrossRef]

21. Puliti, S.; Olerka, H.; Gobakken, T.; Næsset, E. Inventory of Small Forest Areas Using an Unmanned Aerial System. Remote Sens. 2015, 7, 9632-9654. [CrossRef]

22. Wang, C.; Du, H.; Xu, X.; Han, N.; Zhou, G.; Sun, S.; Gao, G. Multi-scale crown closure retrieval for moso bamboo forest using multi-source remotely sensed imagery based on geometric-optical and Erf-BP neural network models. Int. J. Remote Sens. 2015, 36, 1-19. [CrossRef]

23. Mokroš, M.; Výbošt'ok, J.; Merganič, J.; Hollaus, M.; Barton, I.; Koreň, M.; Tomaštík, J.; Čerňava, J. Early Stage Forest Windthrow Estimation Based on Unmanned Aircraft System Imagery. Forests 2017, 8, 306. [CrossRef]

24. Liang, X.; Jaakkola, A.; Wang, Y.; Hyyppä, J.; Honkavaara, E.; Liu, J.; Kaartinen, H. The use of a hand-held camera for individual tree 3D mapping in forest sample plots. Remote Sens. 2014, 6, 6587-6603. [CrossRef]

25. Forsman, M.; Börlin, N.; Holmgren, J. Estimation of Tree Stem Attributes Using Terrestrial Photogrammetry. Forests 2016, 7, 61. [CrossRef]

26. Mikita, T.; Janata, P.; Surový, P. Forest stand inventory based on combined aerial and terrestrial close-range photogrammetry. Forests 2016, 7, 165. [CrossRef]

27. Surový, P.; Yoshimoto, A.; Panagiotidis, D. Accuracy of reconstruction of the tree stem surface using terrestrial close-range photogrammetry. Remote Sens. 2016, 8, 123. [CrossRef]

28. Fang, R.; Strimbu, B.M. Stem Measurements and Taper Modeling Using Photogrammetric Point Clouds. Remote Sens. 2017, 9, 716. [CrossRef]

29. Liang, X.; Kankare, V.; Hyyppä, J.; Wang, Y.; Kukko, A.; Haggrén, H.; Yu, X.; Kaartinen, H.; Jaakkola, A.; Guan, F.; et al. Terrestrial laser scanning in forest inventories. ISPRS J. Photogramm. Remote Sens. 2016, 115, 63-77. [CrossRef]

30. Panagiotidis, D.; Surový, P.; Kuželka, K. Accuracy of Structure from Motion models in comparison with terrestrial laser scanner for the analysis of DBH and height influence on error behaviour. J. For. Sci. 2016, 62, 357-365. [CrossRef]

31. Koreň, M.; Mokroš, M.; Bucha, T. Accuracy of tree diameter estimation from terrestrial laser scanning by circle-fitting methods. Int. J. Appl. Earth Obs. Geoinf. 2017, 63, 122-128. [CrossRef]

32. Koreň, M. DendroCloud: Point Cloud Processing Software for Forestry, Version 1.45, Zvolen. 2017. Available online: http://gis.tuzvo.sk/dendrocloud/download/dendrocloud_1_45.pdf (accessed on 30 January 2018).

33. Liang, X.; Wang, Y.; Jaakkola, A.; Kukko, A.; Kaartinen, H.; Hyyppä, J.; Honkavaara, E.; Liu, J. Forest data collection using terrestrial image-based point clouds from a handheld camera compared to terrestrial and personal laser scanning. IEEE Trans. Geosci. Remote Sens. 2015, 53, 5117-5132. [CrossRef]

34. Pfeifer, N.; Winterhalder, D. Modelling of tree cross sections from terrestrial laser scanning data with free-form curves. Int. Arch. Photogramm. Remote Sens. Spat. Inf. Sci. 2004, 36, 76-81. 
35. Åkerblom, M.; Raumonen, P.; Kaasalainen, M.; Casella, E. Analysis of geometric primitives in quantitative structure models of tree stems. Remote Sens. 2015, 7, 4581-4603.

36. Astrup, R.; Ducey, M.J.; Granhus, A.; Ritter, T.; von Lüpke, N. Approaches for estimating stand-level volume using terrestrial laser scanning in a single-scan mode. Can. J. For. Res. 2014, 44, 666-676. [CrossRef]

37. Ducey, M.J.; Astrup, R. Adjusting for nondetection in forest inventories derived from terrestrial laser scanning. Can. J. Remote Sens. 2013, 39, 410-425.

38. Seidel, D.; Ammer, C. Efficient measurements of basal area in short rotation forests based on terrestrial laser scanning under special consideration of shadowing. iForest-Biogeosci. For. 2014, 7, 227. [CrossRef]

(C) 2018 by the authors. Licensee MDPI, Basel, Switzerland. This article is an open access article distributed under the terms and conditions of the Creative Commons Attribution (CC BY) license (http:/ / creativecommons.org/licenses/by/4.0/). 